\title{
CHARLES MAURON: O GÊNERO CÔMICO COMO FANTASIA DE TRIUNFO
}

\author{
Igor de Almeida Silva \\ Professor do Departamento de Teoria da Arte e Expressão Artística \\ da Universidade Federal de Pernambuco (UFPE). \\ Doutor em Artes pelo Programa de Pós-Graduação em Artes Cênicas \\ da Universidade de São Paulo (2014) \\ Email: ialmeidasilva@uol.com.br
}

O presente artigo propõe-se a abordar a noção de fantasia do triunfo, cunhada pelo crítico francês Charles Mauron, a partir da teoria freudiana do chiste. Busca-se compreender as origens e a natureza desta noção, suas contribuições e limites para os estudos do gênero cômico.

\section{Palavras-chave}

Fantasia de triunfo. Gênero cômico. Psicocrítica. Chiste.
This article proposes to study the notion of fantasy of triumph, coined by the French critic Charles Mauron, from Freud's theory of the joke. It tries to understand the origins and the nature of this notion, their contributions and limits for the comic genre studies.

Keywords

Fantasy of triumph. Comic genre. Psycho-criticism. Joke. 
Desde os primeiros escritos de Freud, constata-se que a prática psicanalítica caracteriza-se, essencialmente, como um trabalho de experimentação entre a fala e o discurso. De modo análogo, o teatro e a literatura são práticas de linguagem capazes de criar "[...] um espaço singular à margem das dificuldades habituais de comunicação [...]" (Marini, 1997, p. 46). Ambas se constituem como formas de intersubjetividade que fundem, em si mesmas, o trabalho da linguagem e do imaginário.

A obra teórica e analítica de Charles Mauron localiza-se na intersecção dessas áreas: a psicanálise, a literatura e o teatro. $O$ termo psicocrítica é criado em 1948 pelo autor "[...] para ressaltar a autonomia de um método que deve forjar 'suas próprias ferramentas' em função de seu objetivo, a produção estética." (Marini, 1997, p. 81). A psicocrítica surge a partir da análise da obra poética de Mallarmé em que, segundo Mauron, "[...] apenas os princípios freudianos de interpretação dos sonhos the pareciam permitir ir mais longe na compreensão da obra e de seus móbeis vitais [...]" (Marini, 1997, p. 81). Dessa forma, pode-se dizer que seu método e seu vocabulário crítico são criados entre Mallarmé e Freud.

A psicocrítica notabiliza-se por partir "[...] ao acaso com os textos, para descobrir a estruturação simbólica de um conflito psíquico que ignora no início [...]" (Marini, 1997, p. 82), tal como no procedimento psicanalítico, mas em detrimento da fruição estética. Por isso, dentre as diversas contribuições da psicanálise ao campo das artes (sobretudo a crítica literária), a psicocrítica de Charles Mauron é o único método específico semelhante, mas não idêntico, à prática analítica, cuja obra essencial é Des métaphores obsédentes au mythe personnel: introduction à la psychocritique (1963).
$\mathrm{Na}$ introdução de seu livro, Psychocritique du genre comique: Aristophane, Plaute, Térence, Molière ([1964] 2000), Mauron esclarece como serão abordados os dois termos que compõem o título da obra, psicocrítica e gênero cômico: "Le premier désigne une méthode, le second un champ d'application."1 (Mauron, 2000 , p. 7). Segundo o ensaísta, a psicocrítica é um método de análise que se propõe a revelar e a estudar as relações inconscientes presentes na tessitura dramática do conjunto de uma obra, que não foram nem pensadas, nem desejadas pelo autor de uma maneira consciente. Ela possibilita o crescimento de nosso conhecimento acerca de textos literários através do discernimento dessas relações, cuja origem só pode ser encontrada racionalmente na personalidade inconsciente do autor.

Tais relações, que permanecem despercebidas na justaposição ou na análise isolada de cada obra, são evidenciadas apenas a partir da sobreposição desses textos. Este procedimento permite a estruturação da obra de um mesmo autor em torno de uma rede de associações ou agrupamento de imagens, obsessivas (repetitivas) e, provavelmente, involuntárias, que averigua coincidências de significantes verbais ou simbólicos entre seus diversos escritos. Essas coincidências seriam repetições de determinados temas, personagens ou situações dramáticas, constituindo metáforas que revelam a lógica do mecanismo inconsciente que as originou. Procura-se também definir como se repetem e se modificam essas redes de associações, reveladas pela primeira operação, pois suas repetições e metamorfoses constituem a imagem de um

1 "O primeiro designa um método, o segundo um campo de aplicação". Todas as traduções do francês são de nossa autoria. 
mito pessoal do autor: "A rede associativa é uma estrutura textual, comum a vários textos e autônoma em relação ao tema consciente de cada um: ela desenha uma 'figura' presente de maneira esparsa em cada texto." (Marini, 1997, p. 83).

O mito pessoal seria a expressão da personalidade inconsciente do escritor. São imagens que resistem à sobreposição de sua literatura ou suas fantasias mais recorrentes, mostrando a evolução de sua psique. Ele exterioriza elementos internos, ao mesmo tempo em que, num movimento contrário, apropriase conscientemente de temas e personagens externos, interiorizados e metamorfoseados pelo artista. O mito pessoal situa-se, portanto, nessa fronteira: "[...] fantasia inconsciente ('constância e coerência estruturada de certo grupo de processos inconscientes') e roteiro pré-consciente que organiza ficções conscientes." (Marini, 1997, p. 87). Seria um trabalho continuo entre a linguagem e o imaginário; consciente e inconsciente.

Entretanto, na psicocrítica aplicada a um gênero, devido à repetição de modelos dramatúrgicos em distintas obras e autores, notamse modificações na definição do mito pessoal: os traços obsessivos recorrentes em diferentes textos não são mais definidos a partir da personalidade inconsciente de um autor, já que esta extravasa de uma dimensão individual para uma coletiva. Também não se justifica exclusivamente pela imitação voluntária de modelos antecessores. O mito pessoal, na psicocrítica de um gênero, reside em elementos específicos presentes em indivíduos de uma mesma cultura. Sua mitologia atinge os arquétipos de um inconsciente coletivo. Por isso, a psicocrítica de um gênero não busca mais ordenar os elementos de uma personalidade, mas identificar e estudar esquemas imaginativos coletivos.

No que concerne ao gênero cômico, o autor restringe sua abordagem ao teatro, excluindo um sentido mais geral que abrangeria toda a literatura e, mesmo, toda a arte cômica. No Psychocritique du genre comique, a comédia é definida em oposição à tragédia, levando-se em consideração três critérios: o caráter dos personagens e seus interesses, o desfecho da intriga e a natureza das reações psicológicas que o dramaturgo se propõe a provocar no espectador. Contudo, Mauron considera apenas o último critério como elemento determinante e seguro para a apreensão do sentido da comédia: "Le genre comique groupe les pièces de théâtre visant à exciter, chez le public, certaines réactions psychologiques, à l'exclusion relative de certaines autres"2 (Mauron, 2000, p. 9). Portanto, para Mauron, o que define o gênero cômico é a intencionalidade do autor em produzir efeitos específicos sobre um público alvo, e que, no caso da comédia, a reação mais esperada, mas não exclusiva, é o riso.

O livro em questão, Psychocritique du genre comique, pode ser organizado em três partes: a primeira, aborda os pressupostos teóricos que servem de base ao leitor para a constituição de sua teoria psicocrítica do gênero cômico; a segunda, é a exposição de seu conceito-chave de comédia como uma fantasia de triunfo ou uma reação compensatória/catártica do nosso inconsciente/imaginário ao sonho angustiante que a tragédia representa; e a última parte seria a demonstração e a aplicação de sua teoria/método na análise da comédia clássica francesa, particularmente a obra de Molière, a

2 "O gênero cômico reúne peças de teatro visando a excitar no público certas reações psicológicas, o que pressupõe a exclusão relativa de outras" [tradução nossa]. 
comédia nova latina de Plauto e Terêncio e a comédia nova e antiga grega de Menandro e Aristófanes.

Mauron toma a teoria freudiana do chiste como ponto de partida de seu estudo, tornando-a sua matriz conceitual para a compreensão do riso deflagrado pela comédia e, consequentemente, da própria natureza desse gênero. Para o autor, o riso da comédia é semelhante àquele provocado pelo chiste. Ambos surgem em decorrência de uma contenção de energia, poupada pela eminência de alguma situação angustiante ou ameaçadora, uma tensão mental. Da descarga dessa energia em excesso extravasa o riso: burlam-se as interdições ou temores e relaxa-se ao mesmo tempo em que se descarrega a energia economizada. Isso porque o chiste nos permite explorar no objeto de escárnio "[...] algo de ridículo que não poderíamos tratar aberta ou conscientemente, devido a obstáculos no caminho; ainda uma vez o chiste evitará restrições e abrirá fontes de prazer que se tinham tornado inacessíveis." (Freud, 1996, p. 103).

O grande mérito dessa hipótese é que ela permite a compreensão do riso infantil: "[...] le rire a toujours, chez l'enfant, le caractère d'un triomphe"3. (Mauron, 2000, p. 19). Este triunfo, que proporciona o relaxamento (ou a "expiação de nossas paixões", como já percebera Aristóteles) provém de uma vitória sobre a angústia. Na medida em que a apreensão e o temor da criança são superados, dá-se sua exteriorização através do riso. Por isso, uma mesma careta pode tanto provocar o riso quanto o pânico no bebê, dependendo de sua compreensão e aceitação do jogo que é estabelecido. $\mathrm{Na}$ criança, o triunfo pode ser uma vitória sobre

3 "[...] na criança, o riso tem sempre o caráter de um triunfo". o medo de ser devorado (careta), abandonado ou punido: quando uma criança comete um ato interdito e depois solicita a cumplicidade de um adulto delator ou censor, escapando ao castigo, expressa seu triunfo entre o sorriso de agradecimento e o gargalhar de satisfação e deboche. Dessa forma, Mauron conclui que o prazer do riso, entendido como triunfo, só pode ser medido em relação a um bem-estar de origem infantil já ultrapassado.

Bergson foi, talvez, o primeiro a unir o riso dos adultos ao jogo infantil. Mas ele via o riso essencialmente como uma função social, um censor que vinha reprimir as inadaptações do indivíduo à vida coletiva e à natureza humana:

Para compreender o riso, é preciso coloca-lo em seu meio natural, que é a sociedade; é preciso, sobretudo, determinar sua função útil, que é uma função social. [...] O riso deve corresponder a certas exigências da vida em comum. O riso deve ter uma significação social." (Bergson, 2004, p. 6).

Tal concepção exclui as origens psíquicas do riso que, na sua expressão infantil, escapa dessa noção: o riso do bebê não almeja o castigo de ninguém. Ele brinca e, quanto mais afirma seu prazer diante dos pudores da vida social, mais ele ri. Contudo, conceituar o riso exclusivamente a partir de uma "teoria econômica", eliminando qualquer outra hipótese, só pode abranger as formas infantis desse fenômeno.

No adulto, o riso infantil persiste adaptado ou subordinado a novas circunstâncias. Todavia, o caso mais geral do riso adulto é aquele onde são contrapostas duas representações específicas: uma, calcada na experiência cotidiana, onde o adulto tenta adaptar-se às exigências do meio e a outra, apresentando certos estados infantis, sugerindo, portanto, o 
retorno a um infantilismo ultrapassado. A partir da justaposição desses dois potenciais, pode surgir o riso.

Por meio do jogo do riso, em que se alternam o retorno ao infantilismo e o escárnio, Mauron distingue a comicidade do chiste. $\mathrm{O}$ homem chistoso goza do prazer pelo jogo, pois conduz processos tanto conscientes quanto inconscientes de pensamento, transitando entre um e outro sem se deixar reprimir pelo inconsciente interdito. O chiste dribla esses recalques pela dissimulação do jogo que lhe é inerente.

Para Mauron, o gênero cômico coloca-se antes na categoria de chiste do que de comicidade em geral, por preservar, assim como no chiste, o caráter de jogo e de triunfo sobre o recalcado. Em verdade, ele o ultrapassa em amplitude, riqueza e qualidade estética: "[...] par la franchise d'une régression, qui, sans quitter le plan verbal, revient à la mimique, à la grimace, à la bouffonnerie, à l'exultation, à la danse des jeux enfantins les moins sociaux, les plus primitifs"4. (Mauron, 2000, p. 23).

Sob o aspecto psíquico, o estado do espectador de teatro lembra o do sonhador noturno. A fantasia que o teatro lhe oferece se desenrola sobre o palco, lugar de irrealidades, exercendo uma ação imaginária que o imobiliza diante da cena, potencializando sua imaginação e sua afetividade: isola-o do mundo real. Entretanto, o espectador não sonha por ele mesmo, mas a partir do que é proposto pela cena. Esta proposta apresenta-se como uma espécie de alucinação ou sonho, da qual a plateia participa, projetando sobre o espetáculo as lembranças de suas experiências afe-

4 "[...] pela franqueza de uma regressão, que, sem abandonar o plano verbal, retoma a mímica, a careta, a bufonaria, a exultação, a dança dos jogos infantis menos sociais, mais primitivos". tivas. Por isso, se o que é evocado são conflitos profundos, então, desperta-se o temor e a compaixão, próprios do gênero trágico. Mas se o espectador recusa-se a participar afetivamente dessa fantasia, o sentimento trágico desaparece e a obra perde seu sentido. Assim é que a tragédia aproxima-se muito mais da estrutura do sonho do que da realidade, porém este sonho assume a forma de pesadelo ao pressupor que, para o sucesso de sua influência sobre o público, seja necessário que este aceite a angústia que lhe é oferecida.

Passando da tragédia à comédia, percebe-se uma modificação no equilíbrio psíquico do espectador. Seu interesse desloca-se do sonho para a realidade exterior e cotidiana. Nessa passagem, caso a angústia dê lugar ao riso, novas defesas psíquicas serão colocadas em ação, em detrimento dos conflitos evocados pela cena, agora, cômica. Do pesadelo, passa-se ao prazer do jogo, tal como no chiste, e a plateia, rapidamente advertida dessa mudança, limita sua participação afetiva, ou mesmo, a rejeita seletivamente: “[...] c'est la règle du jeu, et elle détermine l'attitude correcte. [...] On se dispose au jeu comme au sommeil"5. (Mauron, 2000, p. 27). A tragédia assemelhase, portanto, ao sonho, enquanto que a comédia liga-se à estrutura do jogo.

Dois autores da tragédia e da comédia clássicas francesas podem ser úteis aqui: Jean Racine e Molière. Em Andrômaca, Hermione, vítima do seu próprio ciúme e do abandono, expurga sua cólera através da vingança: manda Orestes assassinar Pirro. Racine faz-nos acreditar, ao menos afetivamente, em cada um dos motivos que desencadearam a ação, sob a forma de assassinato, acrescentando-se ain-

5 "[...] é a regra do jogo e ela determina a atitude correta. [...] a pessoa se dispõe ao jogo como ao sono". 
da seus efeitos, o que propicia o envolvimento do espectador e, consequentemente, sua convicção na representação. Em As artimanhas de Scapino, Molière apresenta a vingança do criado astuto sobre seu patrão (cena da paulada que é o ponto culminante da comédia), sem maiores justificativas, além da vingança não provocar nenhuma consequência desastrosa para Scapino. Os motivos e os sentimentos do criado não são desenvolvidos pelo comediógrafo. Ele não se preocupa em desenvolver progressiva e logicamente tais sentimentos até sua culminância na ação do personagem; tão pouco exige a credulidade afetiva do espectador, sua convicção. Pelo contrário, mostra-nos uma lógica irreal onde as consequências da vingança de um criado contra seu senhor podem desaparecer magicamente. Mesmo que a tragédia se encontre muito mais próxima do sonho que a comédia, sobretudo no que concerne ao efeito que esta provoca no espectador, a primeira preserva uma lógica que a aproxima da realidade, respeitando um princípio de verossimilhança, enquanto que a última, mais ligada ao cotidiano, segue outra lógica, que só ligeiramente assemelha-se ao real, mas que demonstra ser apenas uma ilusão, fruto de sua incoerência e do non-sens: "[...] la comédie n'a cure de cette logique réelle. Elle feint parfois de la respecter, mais conserve jalousement son droit à l'absurde: le non-sens joue un rôle trop grand dans le traît d'esprit pour qu'elle y renonce"6. (Mauron, 2000, p. 28).

Este seria um dos primeiros traços que determinariam a passagem da tragédia para a comédia: "[...] le spectateur est rapidement averti qu'il participe mentalement à un jeu et non

6 "[...] a comédia não se importa com esta lógica do real. Ela às vezes finge respeitá-la, mas conserva ciosamente seu direito ao absurdo: o non-sens representa um papel grande demais no chiste para que a comédia renuncie a ele". plus à un rêve"7. (Mauron, 2000, p. 29). Dessa forma, restringindo sua participação afetiva, agora, tem-se acesso ao que antes era vetado à consciência do espectador. Isto caracteriza a liberdade que o jogo propicia: "[...] la plus mythique des tragédies a moins de droits à l'irreáalité que la comédie la plus quotidienne"8. (Mauron, 2000, p. 29). Tal acesso à incoerência exemplifica-se com as tradicionais reviravoltas das situações cômicas.

A reversibilidade seria um movimento ideal, pois escaparia à degradação da energia. $\mathrm{Na}$ esfera do real, esta degradação é um automatismo do qual a vida busca, incessantemente, escapar através do movimento de conservação e de criação. A partir desse ponto de vista, a aquisição da reversibilidade constitui um triunfo, cujos primeiros exemplos podem ser encontrados nos jogos infantis: "[...] le joueur renverse à son gré des relations qui sont à sens unique dans le monde réel"'. (Mauron, 2000, p. 29). Por isso, "[...] toute liberté créatrice implique une certaine destruction des détermination antérieures; le jeu poétique paraît absurde à la pensée rationnelle"10. (Mauron, 2000, p. 29). O autor cômico aproveita essa liberdade oferecida pela aparente incoerência do jogo, assim como o contador de chistes extrai grandes efeitos da mistura do que faz sentido com o non-sens. Dessa forma, chegamos a outra característica essencial que marca a passagem do gênero trágico ao cômico, ou

7 "[...] o espectador é rapidamente avisado de que participa mentalmente de um jogo e não mais de um sonho".

8 "[...] a mais mítica das tragédias tem menos direitos à irrealidade do que a comédia mais cotidiana".

9 "[...] o jogador inverte a seu bel prazer relações que possuem um único sentido no mundo real".

10 "[...] toda liberdade criadora implica uma certa destruição de determinações anteriores; o jogo poético parece absurdo ao pensamento racional". 
seja, do sonho ao jogo: a inversão de situações angustiantes.

Correntemente, esta reviravolta é observada nos jogos infantis, mas também nos sonhos das crianças e dos adultos: o fraco que se torna forte, ou o pobre que vira rico. Também é o princípio da festa carnavalesca. Elas despertam um sentimento de triunfo que deve favorecer ou reforçar um outro triunfo passageiro que é o riso:

[...] la comédie nous apparaît fondée, dans l'inconscient, sur une fantaisie de triomphe, elle-même née du renversement d'un rêve d'angoisse; cette fantaisie, essentiellement enfantine, est projetée sur l'écran de la vie quotidienne"11. (Mauron, 2000, p. 32).

O gênero cômico apresenta-se como a contraface da tragédia. Enquanto o gênero trágico compartilha a angústia com o público, a comédia supera-a através de um delírio de vitória, fazendo prevalecer o princípio de prazer sobre o princípio de realidade. Por isso, a comédia encontra-se intimamente ligada à sua origem dionisíaca e às suas relações profundas com o mito angustiante da tragédia.

Apesar de ser uma contribuição do inconsciente ao cômico, o chiste caracteriza-se como um trabalho do consciente de dissimulação dos instintos hostis e libidinosos que impulsionam a agressão chistosa. Portanto, o chiste é uma máscara ao inconsciente e o estudo de Freud tem como principal objetivo a compreensão desses processos conscientes de mascaramento. Contrapõe-se ao método psicocrítico que se define, justamente, pela ação contrária: o desvelamento das estruturas

11 "[...] a comédia nos aparece fundada, no inconsciente, sobre uma fantasia de triunfo, nascida ela mesma da inversão de um sonho de angústia; esta fantasia, essencialmente infantil, é projetada sobre a imagem da vida cotidiana". inconscientes. Por isso, Mauron compreende o chiste como uma atividade superficial, insuficiente para o entendimento das estruturas profundas da comédia, ou seja, sua origem religiosa, seu fundo mítico comum à tragédia.

A arte cômica em geral possui uma abertura ao divino. Na Antiguidade, pelo menos, ela não era rejeitada. No templo de Dioniso, ambas as máscaras, trágica e cômica, eram erguidas lado a lado, porque o riso era uma das formas de expressão do sentimento religioso. Ressalte-se, inclusive, que as procissões dionisíacas conduziam à comédia. Estas são as perspectivas profundas, ao mesmo tempo, religiosas e estéticas, pelas quais a arte cômica deve ser considerada.

Neste aspecto, a psicocrítica de Mauron parece absorver e redimensionar a função catártica da comédia, já apontada por Aristóteles e redescoberta através da teoria do chiste e da análise do riso infantil: o relaxamento diante de uma tensão mental, que se reverbera num sentimento de triunfo sobre o recalcado, cuja exteriozação se dá-se, sobretudo, pelo riso. No chiste, desvela-se um temor presente, imediato, porém, no gênero cômico, tal sentimento não se restringe ao contexto em que ele é enunciando e corporificado. Ele vem de uma tradição religiosa que remonta às origens da tragédia e da comédia e que se propaga às gerações e épocas posteriores, fazendo parte, portanto, da psique humana. Por isso:

[...] la vrai profondeur de l'art comique doit être plutôt recherchée dans l'inconsciente fantaisie de triomphe recouvrant un mythe angoissant, c'est-à-dire dans la comédie ou plutôt dans son architecture souterraine. Nous allons retrouver là les figures et les fables de la mythologie du rire - les 
lieux communs du répertoire ${ }^{12}$ (Mauron, 2000, p. 56). [grifo nosso].

Comparando as intrigas de autores da comédia clássica francesa, de Jean de Rotrou a Molière, percebe-se que a trama central permanece sempre a mesma: o desenvolvimento do conflito entre o filho apaixonado e o pai autoritário ou avarento. Tal regularidade conduz Mauron à outra conclusão que é essencial à sua definição da fantasia de triunfo e que estabelece vínculos ainda mais profundos entre a tragédia e a comédia. A fantasia de triunfo do gênero cômico, que na psicocrítica corresponde ao seu mito pessoal, segue o seguinte esquema: "[...] la comédie procède à l'envers du réel et fait triompher les faibles et les amoureux sur les jaloux et les forts, parce ce qu'elle inverse également le sentiment de culpabilité dû au complexe d'OEdipe"13. (Corvin, 1994, p. 200).

$\mathrm{Na}$ tragédia de Édipo, encontramos o herói absorvido por um violento sentimento de culpa. Entretanto, no cerne dessa fábula, pode-se reconhecer a intriga cômica mais banal, cuja finalidade seria libertar o herói dessa mesma angústia. Reencontramos, portanto, sob formas atenuadas dois componentes clássicos; o conflito com o pai e o incesto: "[...] on assiste à la rivalité des mâles pour la possession de la même femme, ce qui, en comédie, est l'équivalent de l'inceste tragique; et le parricide

12 "[...] a verdadeira profundidade da arte cômica deve ser preferencialmente pesquisada na inconsciente fantasia de triunfo recobrindo um mito angustiante, quer dizer na comédia ou, melhor, na sua arquitetura subterrânea. Nós aí encontraremos as figuras e a fábulas da mitologia do riso - os lugares comuns do repertório". [grifo nosso].

13 "[...] a comédia procede ao contrário do real e faz triunfar os fracos e os apaixonados sobre os ciumentos e os fortes, porque ela inverte igualmente o sentimento de culpa devido ao complexo de Édipo". est remplacé par la défaite du Père"14. (Corvin, 1994, p. 200). Dessa forma, escapa-se ao sentimento de culpa e obtêm-se satisfações vagamente ilícitas que caracterizam a intriga como um chiste.

Todavia, os componentes que constituem o mito de Édipo não podem ser explorados de maneira direta na comédia de Molière. $\mathrm{O}$ incesto, representado a partir de uma rivalidade amorosa entre pai e filho, é mascarado ou representado indiretamente pela oposição entre o velhaco licencioso e o jovem galante. Esta dissimulação mostra-se mais adequada à moral que rege a realidade cotidiana sob a qual o comediógrafo projeta sua fantasia. Segundo Mauron, estas duas figuras encontramse como o eixo de diversas comédias sob variações diversas. Na comédia nova de Plauto, repete-se a dinâmica onde o jovem consegue ludibriar o velho petulante em detrimento do mesmo objeto amoroso: uma jovem (geralmente, a filha ou a protegida do velho). As mesmas rivalidades opõem-nos e os pais (velhos) são sempre vencidos. Nesse constante triunfo dos filhos (jovens), existe uma defesa específica contra uma angústia profunda reencontrada nos mitos trágicos: Prometeu ou Édipo.

Portanto, o pesadelo original é o do rebelde ou parricida castigado. Invertido pelo mecanismo de defesa, o gênio cômico transforma a melancolia e a angústia da tragédia em fantasia de vitória, abandonando o sonho e a participação afetiva do leitor-espectador. Em lugar do onírico, projeta-se a vida cotidiana, enquanto que Zeus e Laio assumem o papel de velhaco e o jovem conquistador busca roubar seu fogo sagrado, agora transformado em

14 "[...] assistimos à rivalidade de machos pela posse da mesma fêmea, o que, na comédia, é o equivalente do incesto trágico; e o parricida é substituído pela derrota do Pai”. 
ouro ou na mulher desejada. Enfatizando esse movimento de inversão deflagrado pela força cômica, Mauron diz: "[...] dans la tragédie [...] la culpabalité repose sur le fils, dans la comédie, sur le père. II y a eu renversement. Le père est celui qui dérange l'amour: tel est le contenu latent de la plupart des comédies"15. (Mauron, 2000, p. 58).

Contudo, a figura do pai, como a representação de uma imagem opressora, surge apenas na Comédia Nova. Esta função não Ihe é atribuída em Aristófanes. Para o comediógrafo grego e em toda a comédia antiga, a realidade encontra-se fora do seio da família, nos aspectos políticos que diziam respeito aos cidadãos e à pólis. Ela permanece exterior às questões domésticas: "Il n'est pas question chez Aristophane de triompher du Père, mais plutôt de retrouver la Mère, sous forme, symbolique, de Cité restaurée dans ses vertus anciennes"16 (Corvin, 1994, p. 201). O domínio privado, ou seja, familiar, destaca-se, na Comédia Antiga, como fonte de prazer e não de desprazer e conflito: "Mas esses polos seriam invertidos na Atenas vencida e humilhada do século IV. O espectador deixa de ser um cidadão envolvido nos destinos da pólis e passa a cuidar de seus interesses individuais" (Mendes, 2008, p. 141). Na comédia nova, o princípio de realidade reina na casa. O puro prazer encontra-se agora do lado de fora, fazendo do mundo exterior um lugar de aventuras, negócios malsucedidos e encontros amorosos. Encontra-se na Comédia Nova, segundo Mauron, a principal fonte das imagens obsessivas que,

15 "[...] na tragédia [...] a culpa recai sobre o filho, na comédia, sobre o pai. Deu-se a inversão. O pai é aquele que perturba o amor: esse é o conteúdo latente da maioria das comédias".

16 "Em Aristófanes, não se trata de triunfar sobre o Pai, mas antes de reencontrar a Mãe, sob a forma simbólica da Cidade restaurada em suas antigas virtudes". no gênero cômico, configuram-se em uma fantasia de triunfo.

A passagem da Comédia Antiga para a Nova, ou de Aristófanes para Menandro e, consequentemente, para Plauto, representa uma ruptura e inversão em que se trocam as referências de prazer e realidade, configurando-se em uma nova topografia da fantasia de triunfo, na qual se restringe a cidade para a casa, o público ao privado, alterando os objetivos da comédia, assim como sua tipologia de personagens. Para Mauron, é por intermédio da teoria freudiana do chiste que se pode chegar a esta nova visada acerca do gênero cômico: "La théorie de Freud suit avec précision les contours du mot d'esprit et nous venons de voir qu'on peut, dans une certaine mesure, l'adapter aux contours du genre comique"17. (Mauron, 2000, p. 49).

De fato, a principal contribuição de Charles Mauron aos estudos da comédia está na sua criativa e profunda leitura do gênero cômico como uma inversão alegre das situações angustiantes do mito trágico, daí surgindo a noção de fantasia de triunfo. Mas, assim como o método psicocrítico e a teoria freudiana do chiste são extremamente férteis, são também limitadores no que tange ao estudo de um gênero teatral, que atravessa séculos e distintas culturas no mundo ocidental. De certa maneira, o estudioso procura imprimir às teorias da comédia a transcendência e universalidade que determinam as teorias do trágico e os estudos da tragédia. E, nesse sentido, sua abordagem mostra-se limitada tanto pela sua natureza estruturalista quanto pelo escopo de sua pesquisa, que se restringe essencialmente

17 "A teoria de Freud segue com precisão os contornos do chiste e nós acabamos de ver que podemos, numa certa medida, adaptá-la aos contornos do gênero cômico". 
a quatro autores: Aristófanes, Plauto, Terêncio e Molière. Mauron deixa de lado dramaturgos como Shakespeare, Lope de Vega e Ben Jonson. E a limitação temporal de seu corpus é ainda mais inquietante quando se sabe que ele foi contemporâneo de autores como Beckett e lonesco, que poderiam estimular densas análises a partir da noção de fantasia de triunfo.

Sabe-se também que a recorrência de situações e tipos cômicos da Comédia Nova ao longo da história do teatro ocidental deve-se, sobretudo, ao percurso da recepção da herança cultural greco-latina no Ocidente. O mundo antigo grego foi eclipsado e deglutido pelos latinos que são os responsáveis pela sua transmissão ao longo dos séculos. E no Império Romano, o modelo importado foi naturalmente o da Comédia Nova, mais condizente com o seu regime político-administrativo, em que as questões políticas e sociais são interditas, restando apenas a esfera burguesa como matéria-prima da criação cênica. Portanto, se em Molière, ou em Shakespeare, o espectro da Comédia Nova se faz presente é devido à formação erudita que então vigorou no mundo ocidental, baseada no estudo da língua e cultura latinas.

Apesar de seus limites, o Psychocritique $d u$ genre comique notabiliza-se ainda como um livro fundamental para o estudo da comédia, sendo citado e comentado em boa parte das pesquisas dedicadas ao assunto. Suas análises representam apropriação original da teoria freudiana do chiste, além de se opor à interpretação bergsoniana do riso e da comicidade, "[...] que reduz o prazer cômico à função de punir os vícios da insociabilidade [...].”. (Mendes, 2008, p. 144).

A fantasia de triunfo define-se como um desejo de revanche sobre a realidade. Ela serviria para nos oferecer uma contrapartida espiritual ou imaginária de todos os nossos constrangimentos, opressões e violências causadas pela vida cotidiana, desde nossa primeira educação até nossos conflitos atuais. E, neste caso, a comédia seria a fonte que propiciaria a realização desse desejo. O que distingue a fantasia de triunfo do chiste é que, na primeira, há uma derrota imaginária da realidade que resulta em nós o sentimento de triunfo, enquanto que, na segunda, ocorre uma verdadeira economia de energia provocada por uma interdição atual, momentaneamente transgredida, e que se expressa por intermédio do riso. Portanto, a fantasia de triunfo não é, necessariamente, fonte do riso, embora uma não exclua a outra. O chiste também pressupõe um sentimento de triunfo; no entanto, essa vitória surge em decorrência de uma momentânea superação do recalcado, cujos procedimentos psíquicos são diversos da fantasia de triunfo. Geralmente, tende-se a confundi-los; porém, enquanto a fantasia de triunfo tem sua fonte nas profundezas do inconsciente, o chiste surge de representações atuais, rápidas e precisas. Seu parentesco dá-se como consequência da unidade do próprio gênero cômico.

Referências

BERGSON, Henri. O riso: ensaio sobre a significação da comicidade. Tradução: Ivone Castilho Benedetti. São Paulo: Martins Fontes, 2004.

CORVIN, Michel. Lire la comédie. Paris: Dunod, 1994. 
FREUD, Sigmund. Os chistes e sua relação com o inconsciente. In: . Edição Standard brasileira das Obras psicológicas completas de Sigmund Freud (1905). Tradução: Jayme Salomão. Rio de Janeiro: Imago, 1996. v. 8.

MARINI, Marcelle. A crítica psicanalítica. In: BERGEZ, Daniel et al. Métodos críticos para a análise literária. Tradução: Olinda Maria Rodrigues Prata. São Paulo: Martins Pontes, 1997.

MAURON, Charles. Psychocritique du genre comique: Aristophane, Plaute, Térence, Molière. 4. ed. Paris: José Corti, 2000.

MENDES, Cleise Furtado. A gargalhada de Ulisses: a catarse na comédia. São Paulo: Perspectiva; Salvador: Fundação Gregório de Mattos, 2008. Aprovado em: 29/09/2016 